\title{
Distribution and modes of occurrence of uranium in coals of Eastern Yunnan, China
}

\author{
Xin Wang ${ }^{1}$ Qiyan Feng ${ }^{2}$ Qingjun $\mathrm{Meng}^{2} \cdot$ Fei Liu ${ }^{1} \cdot$ Qihang Cao $^{1} \cdot$ \\ Guijian Liu $^{3}$
}

Received: 1 January 2020/Revised: 31 December 2020/Accepted: 2 July 2021 / Published online: 22 August 2021

(C) The Author(s) 2021

\begin{abstract}
Uranium is an environmentally hazardous element, and is commonly present at trace levels $(2.4 \mu \mathrm{g} / \mathrm{g}$ for world coals) in coal deposits. However, selected coal deposits could be highly enriched in uranium. In this study, 15 coal samples were collected from Eastern Yunnan coal deposits, China, aiming to characterize the distribution and the occurrence of uranium in those coals. In studied samples, uranium content varied from 0.36 to $8.28 \mu \mathrm{g} / \mathrm{g}$, with an average value of $3.76 \mu \mathrm{g} / \mathrm{g}$. Generally, uranium content in coals from northern coal mines $(3.02 \pm 2.44 \mu \mathrm{g} / \mathrm{g}, n=5)$ were lower than it in southern coal mines $(4.13 \pm 2.30 \mu \mathrm{g} / \mathrm{g}, n=10)$. Uranium in coal samples showed no obvious correlation with total sulfur, whereas was positively correlated with ash yield. The results of sequential chemical extraction procedure confirm that organic-bound is the dominant occurrence of uranium. The slight enrichment of uranium in studied coals was probably attributed to sedimentation processes, hydrological conditions and tectonic structure of the coal deposits.
\end{abstract}

Keywords Coal · Uranium · Distribution · Eastern Yunnan · China

\section{Introduction}

Uranium ( $\mathrm{U}$ ) is a naturally radioactive element. Its abundance in Earth's crust is calculated to be $2.5 \mu \mathrm{g} / \mathrm{g}$ and $0.93 \mu \mathrm{g} / \mathrm{g}$ for upper and lower curst, respectively (Wedepohl 1995). High levels of uranium and its radioactive daughters have been observed in several coal deposits (Ahmed et al. 2020; Duan et al. 2018). For example, the Drama lignite deposit in Northern Greece (Megalovasilis et al. 2013) and Yunnan Late Permian coal deposit, China,

Guijian Liu

lgj@ustc.edu.cn

1 College of Life Sciences, Huaibei Normal University, Huaibei 235000, China

2 School of Environment Science and Spatial Informatics, China University of Mining and Technology, Xuzhou 221116, China

3 CAS Key Laboratory of Crust-Mantle Materials and the Environments, School of Earth and Space Sciences, University of Science and Technology of China, Hefei 230026, China have been observed to have uranium content exceeding industrial uranium grade $(200 \mathrm{mg} / \mathrm{g}$ ) (Huang et al. 2012). High-U coals have attracted much attention for industrial utilization (Dai et al. 2016, 2017, 2018). At the beginning of the 'nuclear era' (1960s), intensive efforts had been made to explore U-bearing coals as a uranium source. However, with the discovery of other high-quality raw uranium resources, the interest in U-bearing coals diminished. Nevertheless, U-bearing coals and their combustion products can still potentially be future unconventional nuclear sources (Lauer et al. 2017). During coal combustion, uranium can be concentrated by several folds in the coal combustion products such as slag and fly ash ( $\mathrm{Li}$ et al. 2020; Kumar et al. 2020; Duan et al. 2019; Chen et al. $2017 \mathrm{a}, \mathrm{b})$. At present, uranium in coals is mainly treated as a potentially radioactive contaminate in environment (Talan et al. 2020; Chen 2014; Fujak et al. 2013).

Huang et al. (2012), Dai et al. (2012) and Chen et al. $(2017 \mathrm{a}, \mathrm{b})$ have reviewed the abundance and distribution of uranium in Chinese coals. Chinese U-rich coal deposits are marginally distributed and usually have low reserves (Yang 2007). Mean uranium content in Chinese coals is estimated 
to be $2.43 \mu \mathrm{g} / \mathrm{g}$ (Dai et al. 2012), comparable to its abundance in world coals $(2.4 \mu \mathrm{g} / \mathrm{g}$, Ketris and Yudovich 2009). Uranium is found to be mainly associated with organic matter in low rank coals, while with inorganic minerals in high rank coals (Finkelman et al. 2018).

The coal deposits in Eastern Yunnan, China, have been identified to enrich high levels of uranium (Huang et al. 2012; Wang et al. 2015). However, the enrichment magnitude and extent of uranium are not well studied. In this study, uranium in coal deposits of this area is re-analyzed. This study focuses on the distribution and modes of occurrence of uranium, and the geological controls on the uranium enrichment. This work represents an effort to generalize an extensive knowledge on the geochemistry of radioactive elements in coals.

\section{Geological setting and sampling}

Eastern Yunnan Province is located at the southern part of the Yangzi craton. This region is composed of intermediate massif and suture zones, and has a quite complicated geological setting due to the existence of extensive faulting (Li et al. 2011). The frequent eruptions of volcanic ashes during geological ages and the alternating marine and terrestrial facies could have led to the geochemical and mineralogical anomalies of coal (Miao 2013). In addition to coal deposits, this area is also abundant in metal resources, such as gold, antimony, germanium, gallium, arsenic, mercury, and thallium. Main coal-forming periods in Eastern Yunnan are Early Carboniferous, Late Permian, Late Triassic and Neogene (Tao et al. 2011). Different ranks of coals, from bituminous to anthracite, have been developed. The frequent eruptions of volcanos during coalforming periods and the alternated marine and terrestrial facies have been suggested to be the main reasons causing the geochemical and mineralogical anomalies of regional coals (Miao 2013).

In order to better represent the uranium distribution with respect to coal resources and ranks, 15 coal samples from 14 active coal mines (Maoergou, Fukanglu, Kelang, Changsheng, Xujiayuan, Shizhuang, Chaoyang, Meitanchong, Xingying, Xiao chongchong, Tuobai, Xiaoheiqing, Xiaoshishan and Gongqing) in Eastern Yunnan were sampled (Fig. 1 and Table 1) according to Chinese Standard for Sampling of Coal Seam (GB/T 482-2008). The Zhaotong region including sample ZT-1 - ZT-5 was in the north of our sampling area, the Qujing region including sample QJ-1 - QJ-7 and Kunming region, Honghezhou region were in the south of our sampling area. Upon collection, all samples were stored in polyethylene bags to preclude contamination and weathering.

\section{Analyses}

Coal samples were air-dried, crushed and passed through a 100-mesh sieve before analysis. Proximate analysis was performed according to Chinese standards (GB/T 212-2008; GB/T 476-2001). The total sulfur and different sulfur forms were determined following Chinese standards (GB/T 214-2007) respectively. Powdered samples were digested using mixed acids before uranium and thorium concentration measurement by inductively coupled-plasma mass spectrometry (ICP-MS). The detection limit of the ICP-MS method for uranium is $0.01 \mu \mathrm{g} / \mathrm{g}$, and the standard deviation for replicate sample digests is less than $10 \%$.

Sequential chemical extraction was one of the most common quantitative methods adopted to determine the modes of occurrence of trace elements in geological and environmental research. The sequential extraction procedure was originally developed to analyze soil samples (Tessier et al. 1979). Afterwards, it had been widely used to study the chemical activity and speciation of diverse materials (Pan et al. 2019). Variants of sequential extraction like BCR-701, the SCEP reported by Dai et al. (2012), and sequential extractions with a float-sink step as described by Davidson (2000) and Huggins FE. (2002) were designed for scientific studies involving the contraposition of multiple elements. Thus, a six-step extraction procedure (shown in Fig. 2) was designed and applied to divide the chemical species into the following six types: waterleachable, ion-exchangeable, organic-bound, carbonatebound, silicate-bound, and sulfide-bound.

\section{Results and discussion}

\subsection{Coal characterization}

The ash yields of studied coals ranged from $4.71 \%$ to $32.12 \%$ (mean $=17.59 \%, n=15)$, and total sulfur content varied between $0.25 \%$ and $4.15 \%$ (mean $=1.67 \%, n=15$ ), majority of the samples were classified as low ash and low to medium sulfur coal. The volatile matter values were generally low for most coals varying from $5.67 \%$ to $23.28 \%$, with the exception of one sample (KM) of the value up to $56.34 \%$. According to the proximate analysis, the studied coal samples were classified into different ranks: lignite, bituminous and anthracite (Table 1).

\subsection{Distribution of uranium in coals}

The highest uranium content was observed in Xiaochongchong mine (ML-1) being $8.28 \mu \mathrm{g} / \mathrm{g}$, whereas the lowest uranium content $(0.36 \mu \mathrm{g} / \mathrm{g})$ was found in Changsheng 


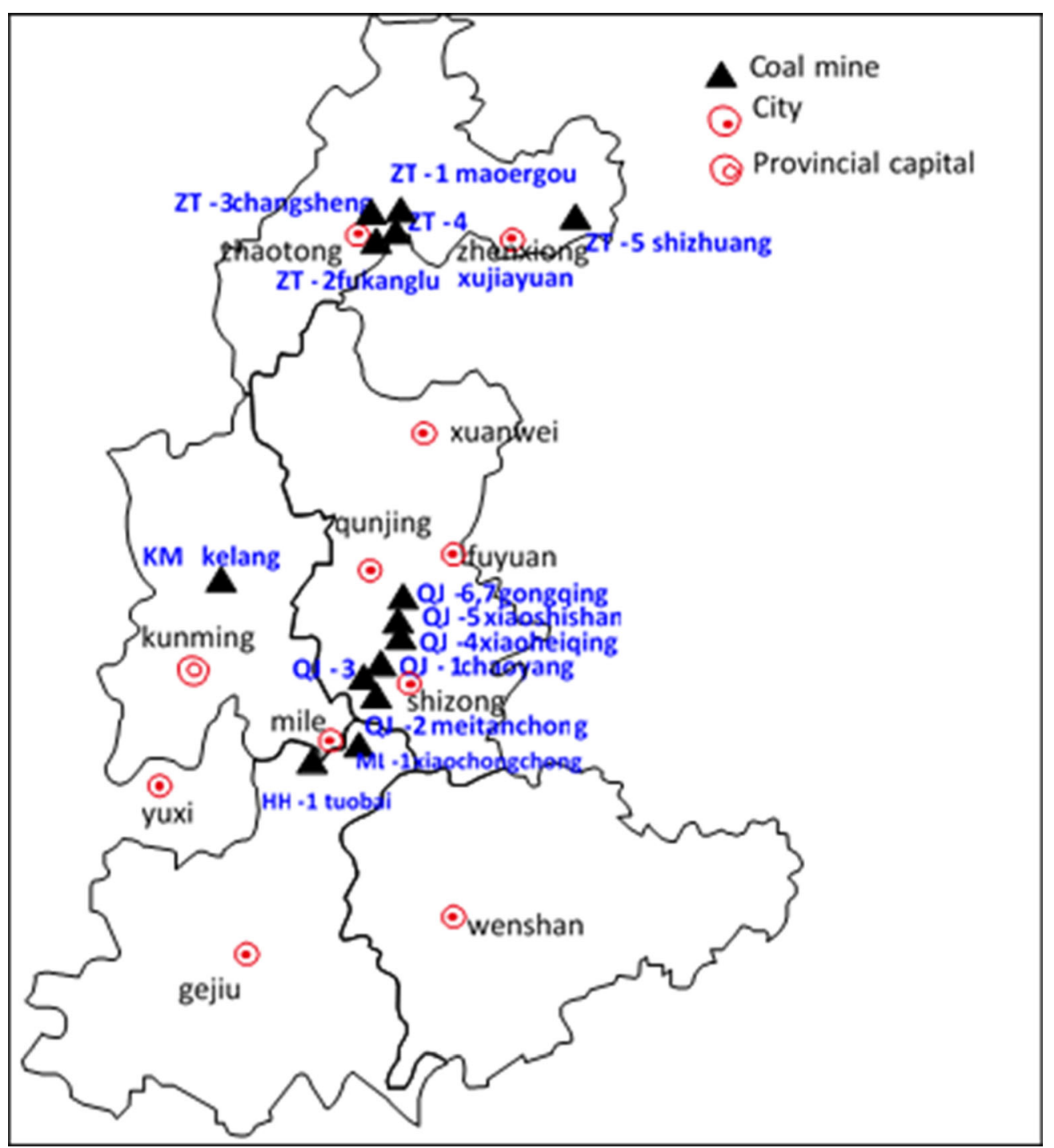

Fig. 1 Sampling locations of the coalmines in Eastern Yunnan, China (ZT: zhaotong, HH: honghezhou, KM: kunming, ML: mile, QJ: qujing)

mine (ZT-3) (Table 1, Fig. 1). The average uranium content in studied coals was $3.76 \mu \mathrm{g} / \mathrm{g}$, slightly higher than that in Chinese coals $(2.71 \mu \mathrm{g} / \mathrm{g})$ (Ren et al. 1999) and world coals $(2.4 \mu \mathrm{g} / \mathrm{g})$ (Ketris and Yudovich 2009), but significantly lower than that in coals from southwestern China $(23.23 \mu \mathrm{g} / \mathrm{g})$ (Huang et al. 2012). As can be seen from Fig. 1, coals from northern coal mines (i.e., Zhaotong region, ZT-1 - ZT-5) had a mean uranium value of $3.02 \mu \mathrm{g} / \mathrm{g}$, which was lower than those from southern mines (i.e., Qujing region, QJ-1 - QJ-7; Kunming, KM; Mile, ML-1; Honghezhou, HH-1) with a mean uranium content of $4.13 \mu \mathrm{g} / \mathrm{g}$. This regional difference in uranium content might be due to the difference in coal ranks. Coal samples from northern mines were anthracite coals in rank, in contrast to the samples from southern mines were lignite and bituminous(GB/T 5751-2009). It had been found that uranium was prone to affiliate with humic acids in coal precursors, which was abundant in low rank coals and depleted in high rank coals (Zhang et al. 2018).

In studied coals, lignite from Kelang mine had a uranium content of $7.32 \mu \mathrm{g} / \mathrm{g}$, significantly higher than the mean value of uranium in the world lignite $(1.51 \mu \mathrm{g} / \mathrm{g})$ (Bouska and Pesek 1999). The average uranium content in nine bituminous samples $(3.78 \mu \mathrm{g} / \mathrm{g})$ was slightly higher than that in the rest five anthracites $(3.02 \mu \mathrm{g} / \mathrm{g})$. Boxplots provided a quick, visual summary about the distribution of uranium in bituminous and anthracites in the Fig. 3. It showed that the median of uranium in the coals of two ranks were nearly eaual and were all higher than the mean value in world coals (Ketris and Yudovich 2009). Therefore, the disribution of uranium in studied coals of different ranks showed no apparent patterns.

The concentration coefficient was defined as the ratio of element concentration in common coals to that in the world 
Table 1 Proximate analysis $(\%)$, sulfur $(\%)$, uranium $(\mu \mathrm{g} / \mathrm{g})$ and radioactive element ratio (U/Th) of the Eastern Yunnan coals

\begin{tabular}{|c|c|c|c|c|c|c|c|c|c|c|c|c|c|}
\hline \multirow[t]{2}{*}{ Sample } & \multirow[t]{2}{*}{ Coal mine } & \multirow[t]{2}{*}{ Coal bed } & \multirow[t]{2}{*}{ Coal rank } & \multirow[t]{2}{*}{ GA* } & \multicolumn{3}{|c|}{ Proximate analysis } & \multirow[t]{2}{*}{$\mathrm{S}_{\mathrm{t}, \mathrm{d}}$} & \multirow[t]{2}{*}{$S_{\mathrm{p}, \mathrm{d}}$} & \multirow[t]{2}{*}{$\mathrm{S}_{\mathrm{s}, \mathrm{d}}$} & \multirow[t]{2}{*}{$\mathrm{S}_{\mathrm{o}, \mathrm{d}}$} & \multirow[t]{2}{*}{$\mathrm{U}$} & \multirow[t]{2}{*}{$\mathrm{U} / \mathrm{Th}$} \\
\hline & & & & & $M_{\mathrm{ad}}$ & $A_{\mathrm{d}}$ & $V_{\text {daf }}$ & & & & & & \\
\hline ZT-1 & Maoergou & M4 & Anthracite & CWF* & 1.20 & 29.24 & 12.66 & 4.00 & 3.65 & 0.18 & 0.17 & 5.50 & 0.57 \\
\hline ZT-2 & Fukanglu & M2 & Anthracite & CWF* & 0.70 & 12.72 & 10.64 & 1.95 & 1.15 & 0.04 & 0.76 & 5.00 & 0.85 \\
\hline KM & Kelang & M8 & Lignite & NEO* & 9.97 & 15.46 & 56.34 & 4.05 & 0.94 & 0.11 & 3.00 & 7.32 & 2.70 \\
\hline ZT-3 & Changsheng & C5 & Anthracite & CWF* & 0.61 & 4.71 & 5.67 & 0.83 & & & & 0.36 & 0.34 \\
\hline ZT-4 & Xujiayuan & $\mathrm{C} 5$ & Anthracite & CWF* & 0.47 & 9.47 & 7.00 & 1.68 & 1.40 & 0.03 & 0.25 & 0.54 & 0.28 \\
\hline ZT-5 & Shizhuang & $\operatorname{mix}$ & Anthracite & PLF* & 0.82 & 32.12 & 12.42 & 3.22 & 2.83 & 0.06 & 0.33 & 3.72 & 0.49 \\
\hline QJ-1 & Chaoyang & C9 & Bituminous & $\mathrm{PXF}^{*}$ & 0.58 & 11.23 & 20.07 & 0.19 & & & & 3.14 & 0.43 \\
\hline QJ-2 & Meitanchong & C9 & Bituminous & PLF* & 0.75 & 10.03 & 19.90 & 0.74 & & & & 3.86 & 0.58 \\
\hline QJ-3 & Xingying & C9 & Bituminous & PLF* & 0.62 & 14.04 & 19.96 & 0.46 & & & & 1.54 & 0.45 \\
\hline ML-1 & Xiaochong chong & C3 & Bituminous & PLF* & 0.86 & 27.03 & 22.91 & 4.15 & 3.41 & 0.30 & 0.44 & 8.28 & 0.95 \\
\hline HН-1 & Tuobai & $\mathrm{C} 10$ & Bituminous & PLF* & 0.55 & 22.81 & 17.99 & 0.48 & & & & 4.76 & 0.57 \\
\hline QJ-4 & Xiaoheiqing & $\mathrm{C} 21$ & Bituminous & PLF* & 0.51 & 18.88 & 16.21 & 1.74 & 1.21 & 0.04 & 0.49 & 1.64 & 0.28 \\
\hline QJ-5 & Xiaoshishan & C15 & Bituminous & PLF* & 0.81 & 25.39 & 23.28 & 0.31 & & & & 4.56 & 0.50 \\
\hline QJ-6 & Gongqing & C16 & Bituminous & PLF* & 0.69 & 10.85 & 22.64 & 0.25 & & & & 4.48 & 0.60 \\
\hline QJ-7 & Gongqing & $\mathrm{C} 18$ & Bituminous & PLF* & 0.75 & 19.81 & 20.48 & 0.93 & & & & 1.74 & 0.46 \\
\hline \multirow[t]{2}{*}{ YN* } & Eastern Yunnan coalfield & & & & & & & & & & & $3.76^{\mathrm{a}}$ & \\
\hline & North-eastern Yunnan coal & & & & & & & & & & & $27.7^{\mathrm{b}}$ & \\
\hline \multirow[t]{3}{*}{$\mathrm{WC}^{*}$} & & & All & & & & & & & & & $2.4^{\mathrm{c}}$ & \\
\hline & & & Lignite & & & & & & & & & $2.9^{\mathrm{c}}$ & \\
\hline & & & Anthracite & & & & & & & & & $1.9^{\mathrm{c}}$ & \\
\hline
\end{tabular}

$G A^{*}$ Geological age, $M$ moisture, $A$ ash yield, $V$ volatile matter, $S_{t}$ total sulfur, $S_{p}$ pyritic sulfur, $S_{s}$ Sulfate sulfur, $S_{o}$ organic sulfur, $a d$ air-dry basis, $d$ dry basis, daf dry and ash-free basis, $C W F^{*}$ Carboniferous Wanshoushan Formation, NEO* Neogene, $P L P^{*}$ Permian Longtan Formation, $P X P^{*}$ Permian Xuanwei Formation, $Y N^{*}$ Yunnan coal

${ }^{\mathrm{a}}$ From Huang W.H., ${ }^{\mathrm{b}}$ From Xi W.S., WC* world coal, ${ }^{\mathrm{c}}$ From Ketris and Yudovich

coals (Avino et al. 2003). Figure 4 showed that only ZT-3 and ZT-4 had concentration coefficients (CC) less than 0.5, indicating a depletion of uranium in these coals (Dai et al. 2014b). Uranium in other samples, including ZT-1, ZT-2, $\mathrm{KM}$ and ML-1, was slightly enriched with CCs of 2-5. Uranium content in the remaining coals was close to the average of world coals $(0.5<\mathrm{CC}<2)$.

\subsection{Modes of occurrence of uranium in coals}

With respect to the sulfur content in coals (GB/T 15, 224.2-2010), the studied coal samples can be classified into four groups: high-sulfur $(>3 \%)$, medium-sulfur $(1.5 \%-2 \%)$, low-sulfur $(0.5 \%-1 \%)$ and super low-sulfur coal $(<0.5 \%)$. The studied coals were characterized as $27 \%$ high-sulfur coal, $20 \%$ medium-sulfur coal, $20 \%$ lowsulfur coal and 33\% super low-sulfur coal. Different sulfur forms were determined in medium and high sulfur coal samples (Table 1). High portion of pyritic sulfur $(58 \%-$ $91 \%$ ) was observed in the coals except one sample (KM), of which $74 \%$ of sulfur was in organic form (Fig. 5).
Sulfur forms in coals throughout the world were highly variable, depending on various geologic conditions (Chou 1997). Previous researchers had carried out detailed studies on the distribution and occurrence of sulfur in various highsulfur coals (Chou 2012; Dai et al. 2013a, b, 2014a, b). The geochemical anomalies, mineralogy, isotopic compositions, and petrology of high-organic-sulfur coals were also extensively reported (Dai et al. 2014a, b). Dai et al. (2008) studied a super high-organic-sulfur (SHOS) Late Permian coal from Yanshan Coalfield, southwestern China, which an evidence of volcanic ash components was found.

Figure 6 indicated that uranium content had no obvious relation with total sulfur in the coal samples $(n=15$, $r=0.43, p>0.05$ ). However, uranium content in medium-high sulfur coal exhibits significant positive correlation with total sulfur as seen in Fig. 7 ( $n=7, r=0.93$, $p<0.01$ ). According to Table 1 , sulfur in coals was dominantly pyritic sulfur except lignite coal (KM). Uranium sometimes created its own mineral forms on the surface of pyrite. Pyrites in such case act as a reducing agent. Previous data including 37 coal samples from other 


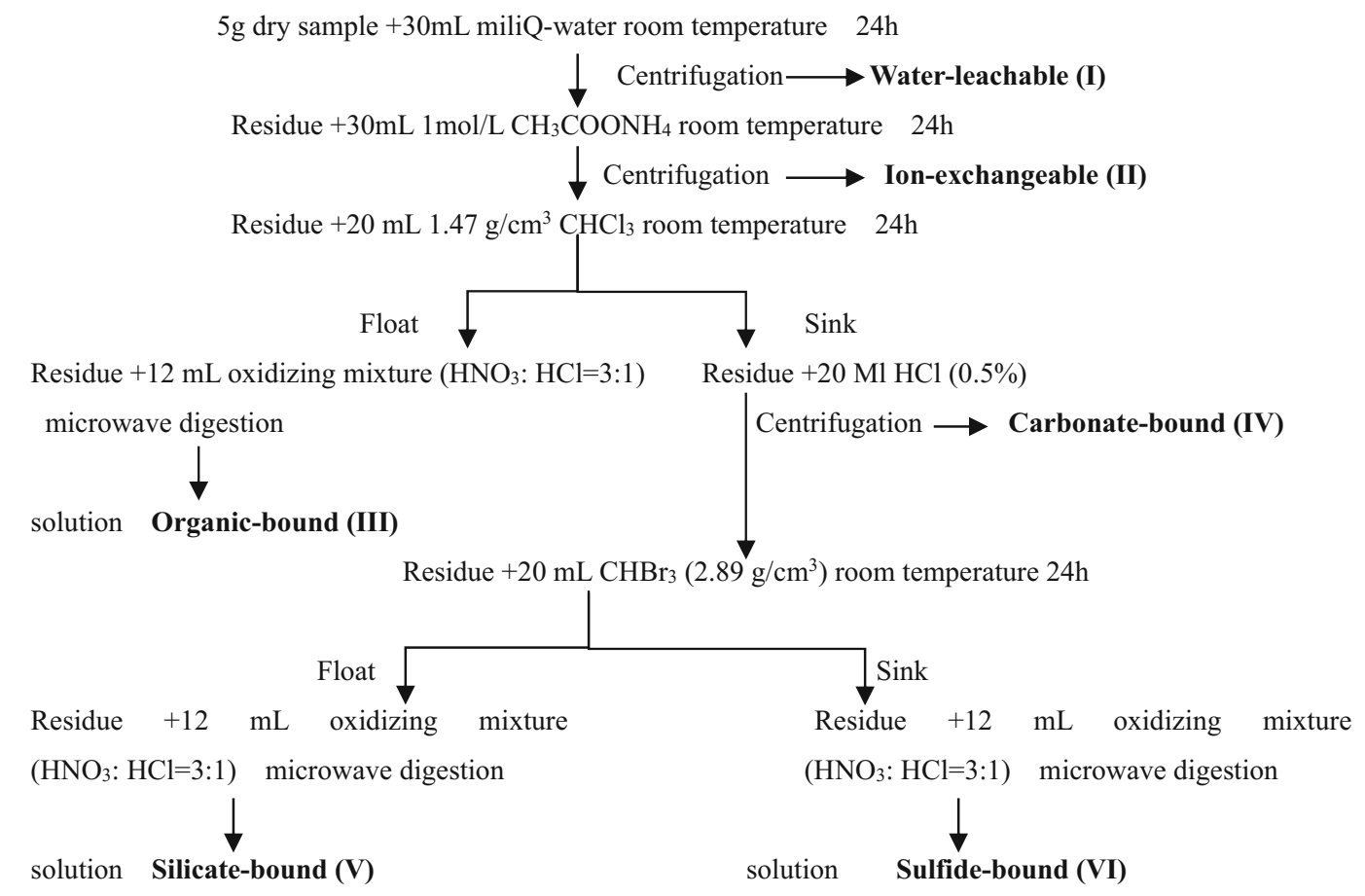

Fig. 2 Diagram of sequential chemical extraction procedure

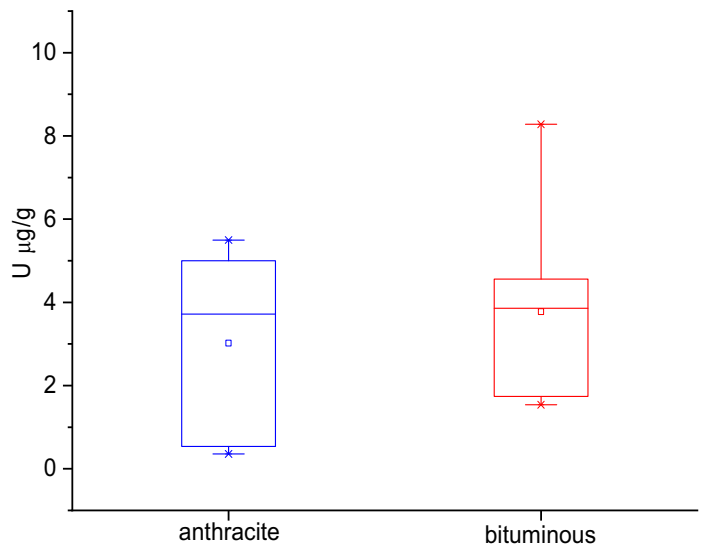

Fig. 3 Distribution of uranium in coals of different ranks in Eastern Yunnan

coal mines in Yunnan Province were compiled together with samples in present study to analyze the relationship between uranium and sulfur (Fig. 8 and Fig. 9) (Tang 2019; Duan 2017; Zhao 2017). It was shown in Fig. 8 that uranium content had no significant relation with total sulfur in coals $(n=52, r=0.51, p<0.01)$. Meanwhile, results shown in Fig. 9 indicated that uranium was not strongly correlated with sulfur in compiled medium-high sulfur coals $(n=39, r=0.58, p<0.01)$ as it found in collected samples of this study $(n=7, r=0.93, p<0.01)$. Therein, 21 coal samples from Ganhe mine were high organic sulfur coals (Zhao 2017), while sulfur in the collected samples of this study was dominantly pyritic sulfur. Thus correlation

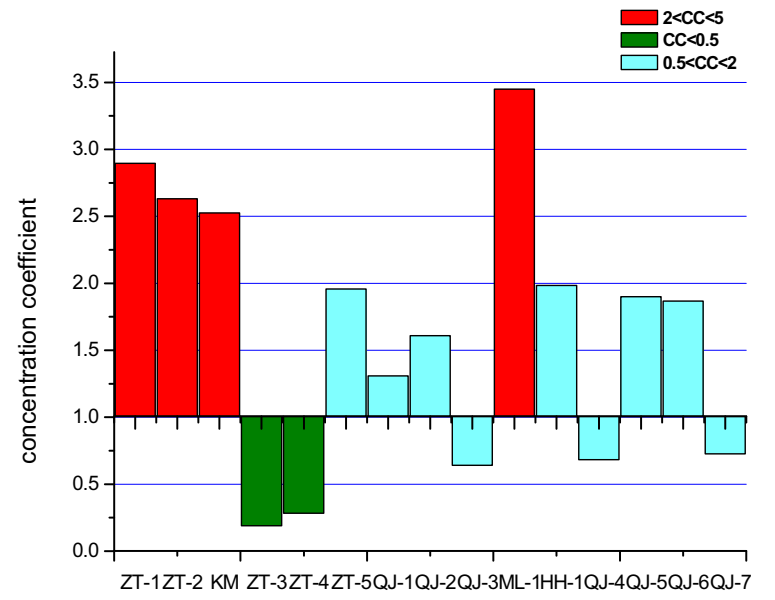

Fig. 4 Concentration coefficients (CC) of uranium in coals of Eastern Yunnan, normalized by average content in the world coals (Ketris and Yudovich, 2009)

of sulfur and uranium content in medium-high sulfur coals was complicated.

\subsection{Association of uranium with ash yield}

The relationship between trace elements and ash yield had been widely reported to deduce the modes of occurrences of selected elements (Dai et al. 2005; Finkelman 1994). It was generally considered that most trace elements in coal were associated with mineral matters (Gentzis and Goodarzi 1997). The ash yield of studied coal samples ranged 


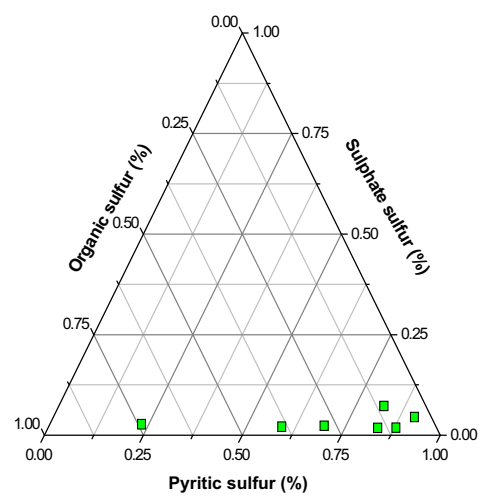

Fig. 5 Ternary diagram of different sulfur forms in medium-high coals

from $4.71 \%$ to $32.12 \%$, with an average value of $17.59 \%$. According to the classification on basis of ash yield (GB/T 15, 224.1-2010) (high ash, > 29\%; medium ash, 16.01\%$29 \%$; low ash, $10.01 \%-16 \%$ and super low ash, $<10 \%$ ), high-ash coal and super low-ash coal accounted for $13 \%$ each, medium-ash coal is $33 \%$, the rest was low-ash coal with $40 \%$. Vassilev et al. (1997) suggested that if there was a positive correlation between studied element in coal and ash yield, this element might be introduced into coal basin by exogenic geological process. Figure 10 showed that uranium in the studied coals had a positive correlation with ash yield ( $n=15, r=0.53, p<0.05)$, thus uranium might be contributed to exogenic geological processes during the coal-forming period, probably due to the water input from the rocks adjacent to coal deposits.

However, on basis of the compiled coals samples, Fig. 11 showed that uranium in Yunnan coals was weakly correlated with ash yield $(n=52, r=0.18, p>0.05)$. Therefore, modes of occurrence of uranium in coals were complicated (Finkelman et al. 2018).

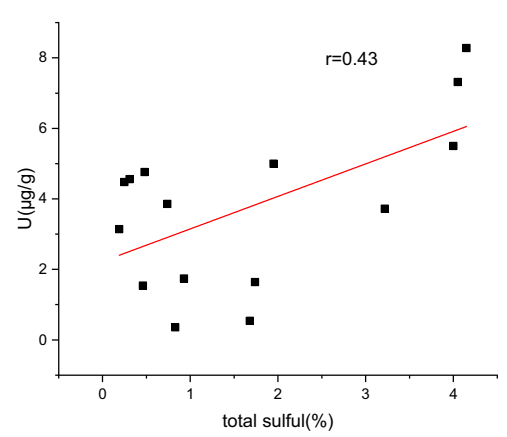

Fig. 6 Correlation between U content and total sulfur in present study

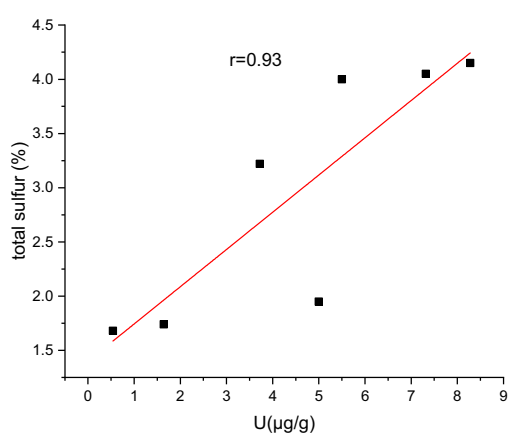

Fig. 7 Variation of the U contents with total sulfur in medium-high sulfur coals

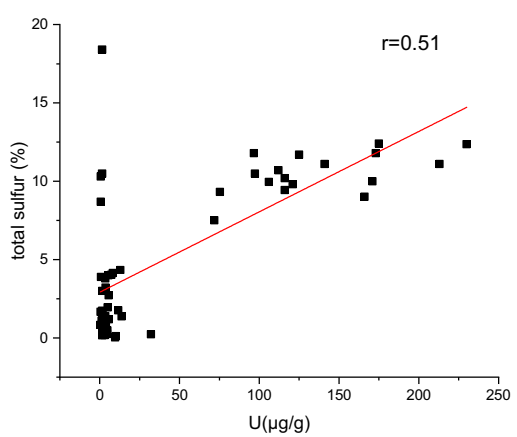

Fig. 8 Correlation between U content and total sulfur in other coals from Yunnan

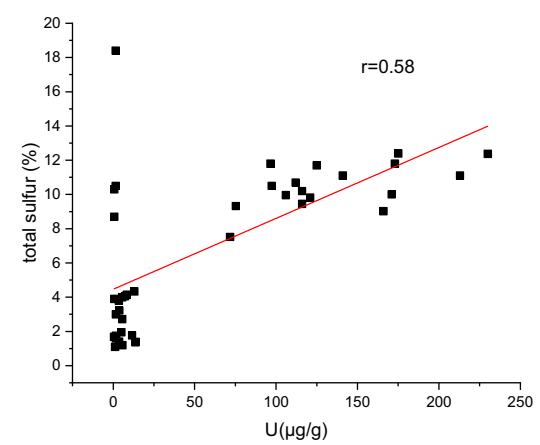

Fig. 9 Correlation between U contents with total sulfur in mediumhigh sulfur coals from other coal mines in Yunnan

\subsection{Results of sequential chemical extraction procedures}

To ascertain modes of occurrence of uranium in coals, sequential chemical extraction procedure (SCEP) was performed. These tests measured the fractional amount of $\mathrm{U}$ in various density fractions that was soluble in a series of increasingly aggressive solvents and acids. Figure 12 showed the experimental results for 7 samples. The uranium recovery during the SCEP for these coals was $99.17 \%$ to $105.07 \%$.

The organic-bound U dominated in KM, QJ-6, ZT-1 and ZT-4, accounting for $72.02 \%, 51.97 \%, 38.5 \%$ and $37.36 \%$ 
of the total $U$, respectively. The ion-exchangeable $U$ was the second most abundant form, accounting for $17.91 \%$, $16.40 \%$ and $20.76 \%$ in $\mathrm{KM}, \mathrm{QJ}-6, \mathrm{ZT}-4$, respectively. However, the second most abundant form of ZT-1 was silicate-bound $\mathrm{U}$, accounting for $26.15 \%$. Unlike samples KM, QJ-6, ZT-1 and ZT-4, silicate-bound U dominated in QJ-3, QJ-7 and ZT-3, respectively accounting for $42.79 \%$, $40.38 \%$ and $38.38 \%$, respectively. Besides, organic-bound $\mathrm{U}$ was the second most abundant form in these coals.

Generally, the main form of uranium was organicbound, followed by silicate-bound, of which the ratio was much lower than the predominant form. Other modes of uranium such as the water-leachable, ion-exchangeable, carbonate-bound, and sulfide-bound were also present however amounted to about $27 \%$ of the total uranium. In consistent with our findings, on basis of the results of SEM-EDX analysis and the sequential solvent extraction experiments, Dai et al. (2008) and Yang (2009) concluded that $\mathrm{U}$ in the M9 coal from Yanshan Coalfield (Eastern Yunnan) was mainly associated with silicate minerals and organic matter. In the same area, Liu et al. (2015) also found $\mathrm{U}$ was mainly dominated by organic association (occupying 78.2\%). Besides, $\mathrm{U}$ in Yantang coals from Xuanwei was present as inorganic minerals as confirmed by SEM-EDX analysis (Shao et al. 2015).

Finkleman R.B. et al. (2018) stated that uranium was associated with the silicates $(40 \%)$ and insoluble phases such as zircon (30\%) in the bituminous coals, but bound to the organics $(55 \%)$ in the low rank coals. Seredin and Finkelman (2008), Arbuzov SI (2012) and Dai et al. (2015) indicated that most of uranium in uranium-bearing coals around the world was bound to organic matter, while uranium in coals with low content below the crustal abundance (clarke) were mainly characterized by the mineral form of occurrence (Yudovich et al. 2002), which was consistent with the results of this study.

\subsection{The genesis of uranium enrichment}

Uranium was much more soluble than thorium in oxidizing surficial and ground waters, leading to a wide uranium

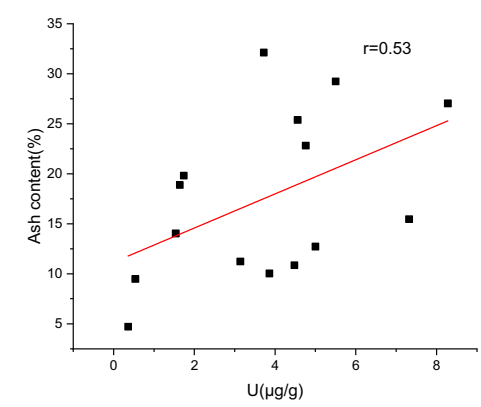

Fig. 10 Correlation between U content and ash yield in present study

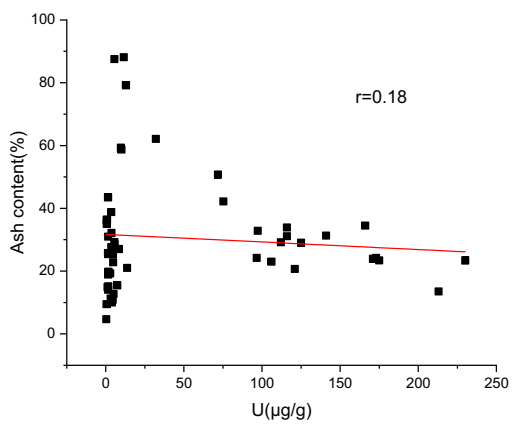

Fig. 11 Correlation between $U$ content and ash yield in other coals from Yunnan

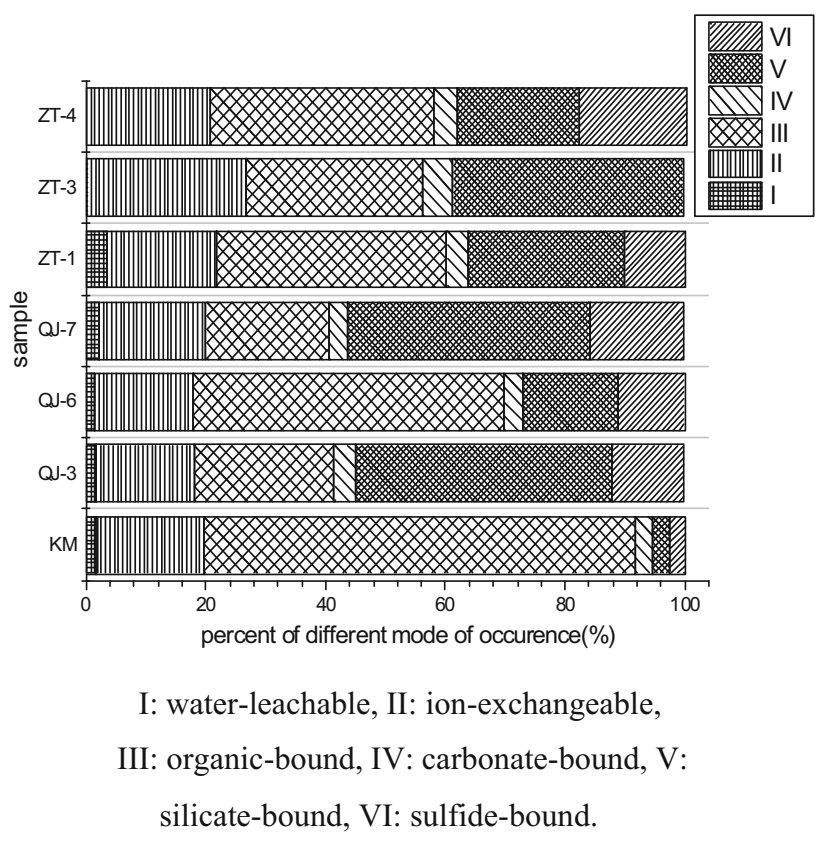

Fig. 12 Results of sequential chemical extraction procedures

content range and, hence, a more variable $\mathrm{U} / \mathrm{Th}$ value in sediments (Hwang and Moon. 2018). Jones and Manning (1994) had reported that the ratio of U/Th less than 0.75 indicated an oxidation environment, while between 0.75 and 1.25 demonstrated a reductive environment. The ratio of U/Th in most of the studied coals in Eastern Yunnan was less than 0.75 (Table 1), indicating that the sedimentary environment was dominated by oxidation environment. Under this condition, uranium was easily oxidized to uranyl ion that was readily soluble and thus active in supergenesis. The uranyl ion can be re-fractioned in surface or ground water (Liu and Cao 1987). Therefore, uranium in studied coals probably derived from water entering the peat swamp during peat formation stages and the ground water interact with the coal seams during/after coalification. However, two samples with U/Th ratios were higher than 0.75 (KM and ML-1). This might be due to the occurrence of sulfate reducing bacteria in the peat swamp, which could 
reduce the dissolved $\mathrm{U}^{6+}$ ions into un-dissolved $\mathrm{U}^{4+}$ irons (Wang et al. 2010). Uranium in water had been thought to be captured by the organic matter in the following ways (Huang et al. 2012). Firstly, the uranyl ion in the water was reduced by organic matter or by the $\mathrm{H}_{2} \mathrm{~S}$ gas generated by organic matter and precipitate in the peat swamp (Finkelman et al. 1994). Secondly, an exchange reaction could take place between $\mathrm{H}^{+}$ions in humic acids and uranyl ions in solution, and then precipitated in coal seams. Thirdly, the uranyl ion could be captured by coal through surface absorption or static electrical -absorption (Zhang 1988).

The enrichment of uranium in coals of Eastern Yunnan could be attributed to the coal forming environment of Eastern Yunnan, which was affected by the facture zone of Mile-Shizong in the southern part of the Yangzi land mass (Miao 2013). As a result, frequent eruptions of volcanic ashes during geological ages and the alternating marine and terrestrial facies could account for the geochemical and mineralogical anomalies of coal (Luo and Zhang 2013). Under these environmental conditions, the evaporation of the seawater probably resulted in the increase of uranium content in coal-bearing sediments.

\section{Conclusions}

Coals sampled from Eastern Yunnan, China, were slightly enriched in uranium compared to the mean values in China and the world coals. Uranium content in studied coals (lignite, bituminous and anthracites) varies from 0.36 to $8.28 \mu \mathrm{g} / \mathrm{g}$. Mean uranium value of coals from northern coal mines is lower than those from southern mines. While the distribution pattern of uranium in studied coals of bituminous and anthracite was not apparent.

A good correlation between the uranium and sulfur content was observed in medium-high sulfur coals. In addition, uranium also showed a good correlation with ash yield, so the uranium could be introduced by exogenic geological process during the coal-forming period, probably due to the water input from the rocks adjacent to coal deposits. Results from sequential chemical extraction procedures showed that the organic-bound was the dominant mode of uranium. The ratio of U/Th in most of the studied coals indicated that the sedimentary environment was dominated by oxidation environment. Therefore, uranium in studied coals probably derived from water entering the peat swamp during peat formation stages and the ground water interact with the coal seams during/after coalification. Furthermore, the mechanisms of uranium enrichment in coals of Eastern Yunnan deserved further research.

Acknowledgements This work was supported by the National Basic Research Program of China (2014CB238903), the National Natural
Science Foundation of China (41173032, 41371444, 41373110), the open project of Anhui Key Laboratory (ZYZWSW2014011), Anhui Provincial Department of Education University Scientific Research Project (KJ2020A1204). We acknowledge editors and reviewers for polishing the language of the paper and for in-depth discussion.

Open Access This article is licensed under a Creative Commons Attribution 4.0 International License, which permits use, sharing, adaptation, distribution and reproduction in any medium or format, as long as you give appropriate credit to the original author(s) and the source, provide a link to the Creative Commons licence, and indicate if changes were made. The images or other third party material in this article are included in the article's Creative Commons licence, unless indicated otherwise in a credit line to the material. If material is not included in the article's Creative Commons licence and your intended use is not permitted by statutory regulation or exceeds the permitted use, you will need to obtain permission directly from the copyright holder. To view a copy of this licence, visit http://creativecommons. org/licenses/by/4.0/.

\section{References}

Ahmed U, Joubert A, Wagner N (2020) Quantification of U, Th and specific radionuclides in coal from selected coal fired power plants in south africa. PLoS ONE 15(5):e0229452

Arbuzov SI, Maslov SG, Volostnov AV et al (2012) Modes of occurrence of uranium and thorium in coals and peats of Northern Asia. Solid Fuel Chem 46(1):52-66

Avino P, Brocco D, Lepore L, Pareti S (2003) Interpretation of atmospheric pollution phenomena in relationship with the vertical atmospheric remixing by means of natural radioactivity measurements (radon) of particulate matter. Ann Chim-Rome 93:589-594

Bouska V, Pesek J (1999) Quality parameters of lignite of the North Bohemian Basin in the Czech Republic in comparison with the world average lignite. Int J Coal Geol 40:211-235

Chen J (2014) On the research needed to better characterise natural radioactivity accumulated in the Arctic by long-range atmospheric transport. Radiat Prot Dosim 158:369-372

Chen J, Chen P, Yao D, Huang W, Tang S, Wang K, Liu W, Hu Y, Zhang B, Sha J (2017a) Abundance, distribution, and modes of occurrence of uranium in Chinese coals. Minerals 7:239

Chen J, Chen P, Yao D, Huang W, Tang S, Wang K, Liu W, Hu Y, Li Q, Wang R (2017b) Geochemistry of uranium in Chinese coals and the emission inventory of coal-fired power plants in China. Int Geol Rev 60:621-637

Chou CL (2012) Sulfur in coals: a review of geochemistry and origins. Int J Coal Geol 100:1-13

Chou CL (1997) Geologic factors affecting the abundance, distribution, and speciation of sulfur in coals. Geology of Fossil Fuels. In Proceedings 30th International Geological Congress, pp 47-57

Dai S, Finkelman RB (2018) Coal as a promising source of critical elements: progress and future prospects. Int $\mathrm{J}$ Coal Geol 186:155-164

Dai SF, Ren D, Tang YG, Yue M, Hao LM (2005) Concentration and distribution of elements in Late Permian coals from western Guizhou Province, China. Int J Coal Geol 61:119-137

Dai S, Ren D, Zhou Y, Chou C-L, Wang X, Zhao L, Zhu X (2008) Mineralogy and geochemistry of a superhigh-organic-sulfur coal, Yanshan Coalfield, Yunnan, China: evidence for a volcanic ash component and influence by submarine exhalation. Chem Geol 255:182-194

Dai S, Ren D, Chou C-L, Finkelman R, Seredin VV, Zhou Y (2012) Geochemistry of trace elements in Chinese coals: a review of 
abundances, genetic types, impacts on human health, and industrial utilization. Int J Coal Geol 94:3-21

Dai SF, Zhang WG, Seredin VV, Ward CR, Hower JC, Song WJ, Wang XB, Li X, Zhao LX, Kang H, Zheng LC, Wang PP, Zhou D (2013a) Factors controlling geochemical and mineralogical compositions of coals preserved within marine carbonate successions: a case study from the Heshan Coalfield, southern China. Int J Coal Geol 109:77-100

Dai SF, Zhang WG, Ward CR, Seredin VV, Hower JC, Li X, Song WJ, Wang XB, Kang H, Zheng LC, Wang PP, Zhou D (2013b) Mineralogical and geochemical anomalies of late Permian coals from the Fusui Coalfield, Guangxi Province, southern China: influences of terrigenous materials and hydrothermal fluids. Int $\mathbf{J}$ Coal Geol 105:60-84

Dai SF, Li T, Seredin VV, Ward CR, Hower JC, Zhou YP, Zhang MQ, Song XL, Song WJ, Zhao CL (2014a) Origin of minerals and elements in the Late Permian coals, tonsteins, and host rocks of the Xinde Mine, Xuanwei, eastern Yunnan, China. Int J Coal Geol 121:53-78

Dai SF, Luo YB, Seredin VV, Ward CR, Hower JC, Zhao L, Liu SD, Zhao CL, Tian HM, Zou JH (2014b) Revisiting the late Permian coal from the Huayingshan, Sichuan, southwestern China: enrichment and occurrence modes of minerals and trace elements. Int J Coal Geol 122:110-128

Dai S, Seredin VV, Ward CR et al (2015) Enrichment of U-Se-Mo$\mathrm{Re}-\mathrm{V}$ in coals preserved within marine carbonate successions: geochemical and mineralogical data from the Late Permian Guiding Coalfield, Guizhou. China Mineralium Deposita 50(2):159-186

Dai S, Yan X, Ward CR, Hower JC, Zhao L, Wang X, Zhao L, Ren D, Finkelman RB (2018) Valuable elements in Chinese coals: A review. Int Geol Rev 60(5-6):590-620

Dai S, Zheng X, Wang X, Finkelman RB, Jiang Y, Ren D, Yan X, Zhou Y (2018) Stone coal in China: a review. Int Geol Rev 60(5-6):736-753

Davidson RM (2000) Modes of occurrence of trace elements in coal. Report CCC/36 International Energy Agency Coal Research, London

Duan P (2017) Geochemistry of toxic elements in high-sulfur coal from Southwest China and their partitioning during coal preparation. Ph.D. dissertation. China University of Mining and Technology (Xuzhou) (in Chinese)

Duan P, Wang W, Sang S, Tang Y, Ma M, Zhang W, Liang B (2018) Geochemistry of toxic elements and their removal via the preparation of high-uranium coal in Southwestern China. Minerals (2075-163X) 8(3):83

Duan P, Wang W, Sang S, Tang Y, Zhao X (2019) Leaching behavior and organic affinity of potentially toxic elements $\mathrm{v}, \mathrm{cr}, \mathrm{mo}$, and $\mathrm{u}$ in flotation-cleaned coal from the ganhe mine, china. J Geochem Explor 200:152-158

Finkelman RB (1994) Modes of occurrence of potentially hazardous elements in coal - levels of confidence. Fuel Process Technol 39:21-34

Finkelman RB, Palmer CA, Peipei W (2018) Quantification of the modes of occurrence of 42 elements in coal. Int J Coal Geol $185: 138-160$

Fujak M, Isajenko K, Lipinski P, Piotrowska B, Kwiatkowska I (2013) Radioactivity of the atmospheric aerosols measured in Poland following the accident in the Fukushima Dai-ichi nuclear power plant in 2011. Nukleonika 58:497-503

GB/T 15224.1-2010. Classification for quality of coal-part 1: Ash. Standardization Administration of China. (in Chinese)

GB/T 15224.2-2010. Classification for quality of coal-part 2: Sulfur content. Standardization Administration of China. (in Chinese)

GB/T 212-2008. Proximate analysis of coal. (in Chinese)

GB/T 214-2007. Determination of total sulfur in coal. (in Chinese)
GB/T 476-2001. Ultimate analysis of coal. (in Chinese)

GB/T 482-2008. Sampling of Coal in Seam. (in Chinese)

GB/T 5751-2009. Chinese classification of coals. (in Chinese)

Gentzis T, Goodarzi F (1997) Trace element geochemistry of the Obed Mountain deposit coals, Alberta, Canada. Fuel 76:1491-1501

Huang WH, Wan H, Finkelman RB, Tang XY, Zhao ZG (2012) Distribution of uranium in the main coalfields of China. Energ Explor Exploit 30:819-835

Huggins FE (2002) Overview of analytical methods for inorganic constituents in coal. Int J Coal Geol 50:169-214

Hwang J, Moon SH (2018) Geochemical evidence for K-metasomatism related to uranium enrichment in Daejeon granitic rocks near the central Ogcheon Metamorphic Belt, Korea. Geosci J 22:1001-1013

Jones B, Manning DAC (1994) Comparison of geochemical indexes used for the interpretation of palaeoredox conditions in ancient mudstones. Chem Geol 111:111-129

Ketris MP, Yudovich YE (2009) Estimations of clarkes for carbonaceous biolithes: world averages for trace element contents in black shales and coals. Int J Coal Geol 78:135-148

Kumar S, Zhao M, Zhang H, Rahman MA, Rahman MM (2021) Distribution, contamination status and source of trace elements in the soil around brick-kilns. Chemosphere 263:127882

Lauer N, Vengosh A, Dai S (2017) Naturally occurring radioactive materials in uranium-rich coals and associated coal combustion residues from China. Environ Sci Technol 51:13487-13493

Li J, Cao DY, Lin YC, Tao ZG, Zhang S, Wang J, Yao Z (2011) Study on tectonic analysis of coal controlled structure mode in Yunnan Province. Coal Sci Technol 39:100-103 (in Chinese)

Li M, Jiang B, Miao Q, Wang G, You Z, Lan F (2020) Multi-phase tectonic movements and their controls on coalbed methane: a case study of no. 9 coal seam from Eastern Yunnan, SW China. Energies 13(22):6003

Liu YJ, Cao LM (1987) Introduction to geochemistry. Geology press, Beijing, pp 57-97

Liu J, Yang Z, Yan X, Ji D, Yang Y, Hu L (2015) Modes of occurrence of highly-elevated trace elements in superhighorganic- sulfur coals. Fuel 156:190-197

Luo XY, Zhang YH (2013) Neogene coal-accumulation basin characteristics and genetic types in Yunnan Province. Coal Geol China 25:11-16

Megalovasilis P, Papastergios G, Filippidis A (2013) Behavior study of trace elements in pulverized lignite, bottom ash, and fly ash of Amyntaio power station, Greece. Environ Monit Assess 185:6071-6076

Miao Q (2013) Study on Gas Geology Condition of Coal mines in Yunnan. Coal Industry Publishing House, Beijin, pp 61-75

Pan J, Zhou C, Tang M et al (2019) Study on the modes of occurrence of rare earth elements in coal fly ash by statistics and a sequential chemical extraction procedure. Fuel 237:555-565

Ren DY, Zhao FH, Wang YQ, Yang SJ (1999) Distributions of minor and trace elements in Chinese coals. Int J Coal Geol 40:109-118

Seredin V, Finkelman RB (2008) Metalliferous coals: a review of the main genetic and geochemical types. Int J Coal Geol 76:253-289

Shao LY, Wang J, Hou HH, Zhang MQ, Wang H, Spiro B, Large D, Zhou YP (2015) Geochemistry of the $\mathrm{C} 1$ coal of latest permian during mass extinction in Xuanwei. Yunnan ACTA Geilogica Sinica 89(1):163-179

Talan D, Huang Q (2020) Separation of thorium, uranium, and rare earths from a strip solution generated from coarse coal refuse. Hydrometallurgy 197:105446

Tang Y (2019) Study on the uranium form controlling mechanism during coal combustion. Ph.D. disseratation. China University of Geosciences(Wuhan) (in Chinese) 
Tao ZG, Cao DY, Li J, Shi XY, Lin YC, Wang J (2011) Study on coalfield structural framwork and coal measures hosting pattern in Easthern Yunnan Area. Coal Geol China 23:56-59 (in Chinese)

Tessier A, Campbell PGC, Bisson M (1979) Sequential extraction procedure for the speciation of particulate trace metals. Anal Chem 51(7):844-851

Vassilev SV, Kitano K, Vassileva CG (1997) Relations between ash yield and chemical and mineral composition of coals. Fuel $76: 3-8$

Wang JY, Wang WF, Li J, Qin Y (2010) Deposit features of Ge, Ga and $U$ elements in Northern part of Datong coalfield. Coal Sci Technol 38:117-121 (in Chinese)

Wang X, Feng Q, Fang T, Liu J, Liu G (2015) Geochemical characteristics of uranium in medium to high sulfur coals from eastern Yunnan, China. J China Coal Soc 40:2451-2457 (in Chinese)

Wedepohl KH (1995) The composition of the continental-crust. Geochim Cosmochim Ac 59:1217-1232
Yang JY (2007) Concentration and distribution of uranium in Chinese coals. Energy 32:203-212

Yang Z (2009) Occurrence and abundance of V, Cr, Mo, and U in the late permian coals from Yanshan, Yunnan, China. Bulletin Mineral Petrol Geochem 28(3):268-271 (in Chinese)

Yudovich YaE, Ketris MP (2002) Neorganicheskoeveshchestvo uglei (Inorganic matter of Coal), Yekaterinburg: UrO RAN

Zhang RL (1988) Extracting uranium from coal. Atomic energy press, pp $1-25$

Zhang Y, Li Y, Ning Y et al (2019) Adsorption and desorption of uranium(vi) onto humic acids derived from uranium-enriched lignites. Water Sci Technol 26(20):20277-20285

Zhao YY (2017) The occurrence mode of enriched trace elements and nanominerals in a superhigh-organic-sulfur coal from Ganhe Coalmine, Yanshan Coalfield, Yunnan, China. M.A. dissertation. Taiyuan University of Technology. (in Chinese) 